\title{
Priming Across Modalities and Priming Across Category Levels: Extending the Domain of Preserved Function in Amnesia
}

\author{
Peter Graf \\ University of Toronto, Toronto, Canada
}

\author{
Arthur P. Shimamura \\ Department of Psychiatry, University of \\ California School of Medicine, La Jolla
}

\author{
Larry R. Squire
}

Veterans Administration Medical Center, San Diego and Department of Psychiatry, University of California School of Medicine, La Jolla

\begin{abstract}
Amnesia is considered to reflect the effects of damage to a specific brain system required for elaboration, consolidation, and conscious recollection. The study of amnesia is therefore a useful approach for establishing dissociations of function and for understanding the normal organization of memory functions. Amnesic patients and two control groups were tested in two studies of priming. In the first experiment, as measured by a word completion test, all groups exhibited significant priming effects that were greater within a modality than across modalities. The amnesic patients exhibited normal priming effects both within and across modalities, despite severe impairment in recall. In the second experiment, all groups exhibited significant and equivalent priming of category exemplars when category labels were presented and subjects were asked to produce the first exemplars that came to mind. The results extend the domain in which preserved priming effects can be observed in amnesia and they suggest that features of priming observed in normal subjects describe a capacity that is independent of the brain system damaged in amnesia.
\end{abstract}

Studies of amnesia have provided significant insights into the organization of normal memory (for reviews, Cermak, 1982; Rozin, 1976; Squire \& Butters, 1984; Squire \& Cohen, 1984; Talland, 1965). Recently, studies of new learning capacity in amnesic patients have provided compelling evidence for a distinction between two kinds of memory. These studies showed that amnesic patients are severely impaired in learning new facts and episodes-the events of daily life-yet they are entirely normal in learning perceptualmotor and cognitive skills (Brooks \& Baddeley, 1976; Cohen, 1984; Cohen \& Squire, 1980; Corkin, 1968). For example, amnesic

The research was supported in part by Medical Research Service of the Veterans Administration and NIMH Grant MH24600, by a postdoctoral fellowship and research grant UO229 from the Natural Sciences and Engineering Research Council of Canada to Peter Graf, and by NIMH National Research Services Award MH08992 to Arthur P. Shimamura. We thank Joyce Zouzounis, Brian Leonard, Armand Bernheim, and Patty Feldstein for their research assistance.

Request for reprints should be sent to Larry R. Squire, Veterans Administration Medical Center (V116A), 3350 La Jolla Village Drive, San Diego, California 92161. patients can acquire at a normal rate the skills involved in reading words from a mirror reversed display, and they can retain this skill at a normal level for a three-month period, despite failing to recognize the same words on a recognition test and failing to recognize the apparatus that was used for testing (Cohen \& Squire, 1980).

In addition to memory for skills, it is now known that amnesia also spares direct or repetition priming - the facilitation in processing an item, such as a written word, that had been presented recently (Cofer, 1967; Cramer, 1966). For example, Graf, Squire, and Mandler (1984) found normal priming on a word completion test that required subjects to complete the first three letters of recently presented words with the first words that came to mind. Both amnesic patients and control subjects produced the recently presented words as completions for the test cues more than 4 times as often as would have been expected if the words had not been presented. In contrast to word completion performance, however, the amnesic patients showed a severe impairment on a free-recall 
test and a word recognition test. This pattern of findings and the results from related studies (e.g., Diamond \& Rozin, 1984; Jacoby \& Witherspoon, 1982; Mortensen, 1980; Schacter, in press; Shimamura \& Squire, 1984; Squire, Shimamura, \& Graf, 1985a; Warrington \& Weiskrantz, 1970, 1974, 1978) indicate that amnesia impairs the ability to recall or recognize words, but it spares the capacity for word priming.

These findings from amnesic patients support the view that the nervous system honors a distinction between two forms of memory, one or more that are spared in amnesia and one that is impaired. Skill learning and priming rely on memory systems or processes that are spared in amnesia, whereas the explicit retention of facts and events, as measured by recall and recognition tests, depends on a different and independent memory system, i.e., a brain system, that is damaged in amnesia (Mishkin, Malamut, \& Bachevalier, 1984; Squire, 1982a). This distinction has been expressed in terms of procedural and declarative memory (Cohen, 1984; Cohen \& Squire, 1980; Squire \& Cohen, 1984). The relationship of this distinction to others that have been proposed is discussed elsewhere (Squire \& Cohen, 1984).

To the extent that amnesia reveals a biologically important division of memory functions, it will be useful to obtain a precise delineation of what amnesic patients can and cannot do. Toward this end, the present study further examined priming in amnesic patients. Previous studies of amnesic patients have reported normal priming effects, but these studies did not explore a number of factors that are important determinants of priming in normal subjects. For example, in normal subjects the perceptual similarity between study list items and test cues influences the magnitude of priming (Clarke \& Morton, 1983; Graf \& Mandler, 1984; Roediger \& Blaxton, 1983; Scarborough, Gerard, \& Cortese, 1979; Winnick \& Daniel, 1970). Specifically, normal subjects show less priming when study words and test cues are presented in different sensory modalities than when they are presented in the same modality (Graf \& Mandler, 1984; Kirsner, Milech, \& Standen, 1983; Roediger \& Blaxton, 1983). This finding indicates that the priming phe- nomenon depends to some extent on modality-specific sensory and perceptual information (Forster, 1976; Jacoby, 1983; Morton, 1969, 1979; Scarborough et al., 1979). At the same time, the finding that normal subjects show some priming when study and testing are in different sensory modalities suggests that some aspects of priming are not tied to modality.

Priming across sensory modalities might be mediated by different memory processes than priming within a sensory modality (Clarke \& Morton, 1983). It is possible, therefore, that only some of these processes are spared in amnesia. Thus, although amnesic patients show normal priming within a modality, they may show no evidence of priming when the study list and test items are presented in different sensory modalities. In contrast, it is possible that priming is mediated by a set of related processes, all of which are spared in amnesia, such that amnesic patients and normal control subjects would show a similar pattern of priming within modality and across sensory modalities.

The study of priming across modalities in amnesic patients can also address questions that have been raised as to whether acrossmodality priming in normal subjects even reflects true priming. A number of authors have argued that priming is strictly a modality-specific phenomenon (Clarke \& Morton, 1983; Scarborough et al., 1979), and they have dismissed priming across sensory modalities as an artifact that arises as a result of subjects' ability to remember the critical study items (see Clarke \& Morton, 1983). Because amnesic patients typically fail to recall a list of words after even a short delay, their performance on a priming test is less likely to be confounded by explicit remembering. Thus amnesic patients could provide stronger evidence for across-modality priming than what can be obtained from normal subjects.

The present study explored these issues in two separate experiments. Both experiments varied the sensory and perceptual similarity between study words and test cues and compared the effects of these variations on test performance in amnesic patients and in control subjects. Experiment 1 compared priming 
for words that were studied and tested in the same sensory modality or in different sensory modalities. Experiment 2 assessed priming for category exemplars (e.g., avocado, raspberry) by presenting category labels as test cues (e.g., fruit) and then asking subjects to produce the first exemplars that came to mind (see Kihlstrom, 1980). The critical issue addressed by both experiments is whether amnesic patients exhibit normal priming when there is little or no overlap of sensory and perceptual information between study items and test cues.

\section{Experiment 1}

Experiment 1 compared amnesic patients and control subjects under within-modality and across-modality priming conditions. Subjects were presented words, either visually or orally, and then they received both a freerecall and word completion test. On the word completion test, the initial three letters of words were shown as cues, and subjects were asked to complete the cues with the first words that came to mind. The question of interest was whether or not amnesic patients would exhibit normal priming under all study-test conditions.

\section{Method}

\section{Subjects}

Amnesic patients. We tested two groups of amnesic patients. One group consited of 3 women and 5 men with alcoholic Korsakoff syndrome. These patients, who averaged 53.8 years of age (range 39-74 years) and 12.4 years of formal education (range 12-14), were residents of chronic care facilities in San Diego County. Their average full-scale Wechsler Adult Intelligence Scale (WAIS) IQ was 102.6 (range 91-114), and their average Wechsler Memory Scale (WMS) score was 78 (range 64-93). In normal subjects, the WMS score is equivalent to the WAIS IQ. Neuropsychological screening and independent neurological examination indicated that memory impairment was the only notable deficit in higher cortical functions. All of these patients could draw a cube and a house in perspective, and none had aphasia or apraxia. The memory impairment shown by this group has been documented in previous studies (Cohen \& Squire, 1981; Graf et al., 1984; Squire, 1982b).

We also tested 2 men who had amnesia of relatively recent onset, caused by hypotensive episodes. One (Case 1) became amnesic in 1976 following a cardiac arrest and a period of unconsciousness [age at testing $=45$ years; formal education $=20$ years (doctorate in clinical psychology); WAIS IQ = 119; WMS = 91]. The second patient (Case 2) became amnesic in 1978 following complications associated with open heart surgery that included a hypotensive episode (age at testing $=56$ years; formal education $=10$ years; WAIS IQ $=111$; WMS $=91$ ) .

All the amnesic patients were characterized by a severe impairment in tests of delayed recall and paired-associate learning. Their scores for immediate and delayed recall (12 $\mathrm{min}$ ) of a short prose passage average 4.5 and 0.5 segments, respectively (21 segments total). Their recall of 10 unrelated noun-noun pairs on each of three successive trials was $0.5,1.0$, and 1.5 .

This description of the amnesic patients is intended to facilitate comparisons between this and other studies of amnesia and to emphasize the severe but circumscribed nature of their memory deficit. However, the main interest here is in overall differences between amnesic patients and control subjects, rather than differences between individual subjects. The data analyses and discussion will therefore focus on the overall pattern of performance on each test.

Control groups. Two control groups were tested in order to assess the performance of the amnesic patients, one group consisting of alcoholic patients, and a second group consisting of medical patients. The alcoholic control group included 8 men who were participating in alcoholic treatment programs in San Diego County. They had been drinking for an average of 18.9 years, they had abstained from alcohol for an average of 6.5 weeks prior to participating in the present study, and they had no history of head injury or liver disease. This group averaged 48.2 years of age (range 40-59), had 13.5 years of formal education (range 12-20), and had a WAIS-R subtest score of 22 for information (18.1 for the amnesic patients) and 49.9 for vocabulary (44.1 for the amnesic patients). Their scores for immediate and delayed recall $(12 \mathrm{~min})$ of a short-prose passage averaged 8.7 and 7.1 segments, respectively. Their recall of 10 unrelated noun-noun pairs on each of three successive trials was 3.9, 7.4, and 8.9.

The second control group consisted of 8 men from the medical and surgical wards of the San Diego Veterans Administration Medical Center. None of these subjects had a psychiatric diagnosis, and none had a history of alcoholism. These patients averaged 50.6 years of age (range 46-56) and had an average of 14.2 years of formal education (range 11-18); they had WAIS-R subtest scores that averaged 22.9 for information (18.1 for the amnesic patients) and 52.8 for vocabulary (44.1 for the amnesic patients).

\section{Materials}

One hundred and ten words were selected from Webster's Pocket Dictionary (average frequency of occurrence per million $=70$, Kučera \& Francis, 1967) and hand printed on index cards in $12 \mathrm{~mm}$ high capital letters. These words were from four to eight letters long. The initial three letters, the "stem" of each word (e.g., ELE, BAS), appeared only once among the set of selected words. The pocket dictionary listed at least 10 common words that could be used to complete each stem. The 110 selected words were divided into 3 sets: Set 1 included 80 words that were assigned to 8 target lists of 10 words each; Set 2 included 20 words that were used as fillers at 
the beginning and end of the target lists to prevent primacy and recency effects; and Set 3 included 10 words that were used for instruction and practice.

\section{Procedure}

The subjects were tested individually. They were first instructed in a task that required rating their like or dislike of words with the aid of a 5-point scale that was displayed continuously in front of them. The ends of this scale were labeled like extremely (1) and dislike extremely (5). This rating task required subjects to analyze the semantic features of the study list words. Subjects practiced this task with words that were presented one at a time, first with five words printed on index cards, and then with five words spoken by the experimenter. Subjects recorded their liking ratings on a blank page. Word presentation was self-paced by each subject's speed on the rating task, about 5 -s per word; previous work has shown that rates of presentation that varied from 3 to 7 $\mathrm{s}$ has littie systematic effects on word completion performance (Graf \& Mandler, 1984).

Immediately after practice, there were four study-test trials, with each trial consisting of two presentations of a study list followed by tests of free recall and word completion. The study list for a trial was presented in a different random order on each presentation, and subjects rated how much they liked each word. The study lists were presented visually on two trials, and auditorily on the other two trials. The presentation modality alternated from trial to trial, with the order of modality counterbalanced across subjects. The word completion test cues were always presented visually. Thus, word completion performance following a visual presentation of the study list provided a measure of within-modality priming, whereas word completion performance following a oral presentation provided a measure of across-modality priming.

Each study list included one 10-word target list from Set 1 and 5 filler words. Three of the fillers were always presented at the beginning and two at the ending of the study list. Immediately after the second study list presentation, subjects were asked to recall the list words and write them on a blank page in any order. Then they were given a word-completion test that showed 20 word beginnings, 10 from the critical study list of target words, and 10 from a target list that had not been presented to the same subject. Subjects were told that each of the completion-test cues was "the beginning of an English word," and they were asked to write a "few letters to make each into a word. You can write any English word-but please write the first word that comes to mind." We urged subjects to write the first words that came to mind, but not to give proper names as cue completions. When a proper name was given, an alternative completion was requested. Subjects usually required only a few seconds to complete each word. When all cues were completed, there was a short pause (about 2-3 $\mathrm{min}$ ) before the next trial was given.

In summary, each subject studied four of the eight target lists, two that were presented in their written form, and two in their spoken form. A recall test was always given immediately after the study phase, followed by a completion test that included the initial three letters of the 10 presented target words, as well as the initial letters of 10 words from one of the four target lists that was never presented to the same subject. The probability of producing target words for the latter word stems provided a measure of baseline completion performance. Across subjects. each target list was presented equally often in each modality. Target lists were also used equally often in study lists and for assessing baseline completion performance.

\section{Results and Discussion}

A strict criterion was used in scoring both the free recall and the completion protocols: words were counted as correct only if they had appeared in a target list in exactly the same form (no plurals, changes in tense, adjectival forms, etc.). Alternative scoring methods did not alter the pattern of findings. In addition, subjects performed similarly on the two study-test trials that were given in each modality, and thus, for the analysis described later, we averaged the results across the two trials. The significance level was set at .05 for all statistical tests.

Figure 1 shows the critical data for amnesic patients and control subjects on the freerecall test and on the word completion test, under both visual-visual and auditory-visual study-test conditions. Overall, average free recall of words was lower for amnesic patients (14.8\%) than for inpatient controls $(37.2 \%)$ or for alcoholic controls (36.9\%). However, in each subject group, a similar percentage of words was recalled under visual-visual and visual-auditory study-test conditions. An analysis of variance (ANOVA) of the recall data showed a significant main effect for subject groups, $F(2,23)=7.36, M S_{\mathrm{e}}=14.8$, with no other effects approaching significance. This pattern of results illustrates the severe memory deficit of the amnesic patients, and it extends to amnesic patients the familiar finding that modality of study list presentation has little or no effect on measures of explicit remembering (Clarke \& Morton, 1983; Graf \& Mandler, 1984; Roediger \& Blaxton, 1983; Scarborough et al., 1979; Winnick \& Daniel, 1970).

Figure 1 also shows the average level of word completion test performance for words that had appeared on the study list and for words that had not been presented. The latter words provided a measure of baseline completion performance. The three subject groups showed similar levels of baseline completion 
RECALL

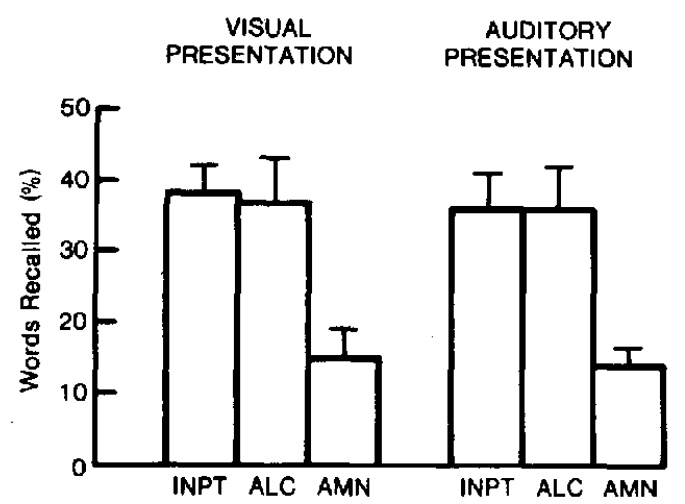

\section{COMPLETION}

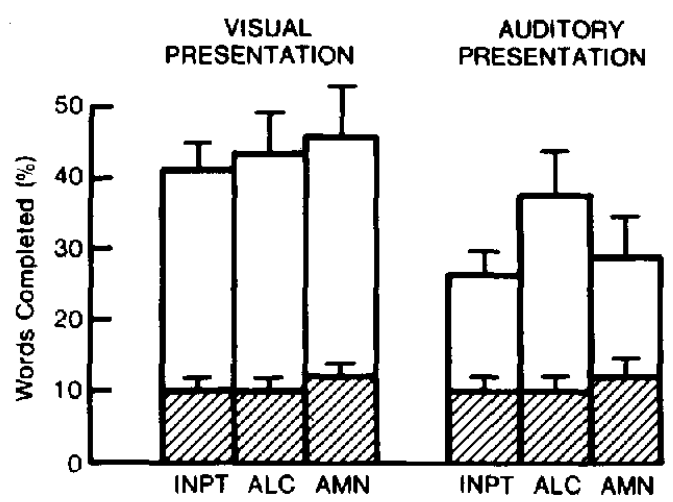

Figure 1. Free recall (left) and word completion (right) by amnesic patients (AMN), medical inpatients (INPT), and alcoholic controls (ALC). [Test cues in the word completion test were always presented visually. Thus, test cues were either in the same sensory modality as the study list items (visual presentation) or in a different sensory modality (auditory presentation). The shaded area of each bar shows baseline performance.]

performance, averaging $10.6 \%, 10.0 \%$, and $12.8 \%$ for the inpatient control group, the alcoholic control group, and the amnesic group, respectively. Figure 1 also indicates that the three groups performed similarly on the critical study-list words. In order to obtain a measure of priming from these word completion test scores, each subject's score on the critical study list words was reduced by his or her baseline score on the target words that had not been presented. These difference scores for word completion differed in two important ways from recall test scores. First, the magnitude of priming was similar across the three subject groups $(23.4 \%, 31.4 \%$, and $26.2 \%$ for inpatient, alcoholic, and amnesic groups respectively), $F(2,23)=.5$, thus replicating the finding that amnesic patients can show normal priming on a word completion test despite their profound deficit on tests that require explicit remembering (Diamond \& Rozin, 1984; Graf et al., 1984; Jacoby \& Witherspoon, 1982; Shimamura \& Squire, 1984, Warrington \& Weiskrantz, 1974).

Second, modality of study list presentation influenced the magnitude of priming for both amnesic patients and control subjects. Priming was greater for words that had been studied and treated in the same modality $(32.9 \%)$ than for words that had been studied and tested in different modalities $(20.9 \%)$, $F(2,23)=12.1, M S_{\mathrm{e}}=6.5$. Although within- modality priming was greater than acrossmodality priming, subjects nevertheless showed significant priming under across-modality conditions (all $t \mathrm{~s}>2.92$ ). The analysis of the completion test data showed no other significant effects. In particular, there was no interaction effect between modality of presentation and subject group.

Finally, we calculated completion performance contingent on recall performance. Averaged over the two types of presentations, word completion performance for words that were correctly recalled was $50 \%, 56 \%$, and $59 \%$ for inpatients, alcoholics, and amnesic patients, respectively. Word completion performance for words not recalled was $25 \%$, $29 \%$, and $31 \%$ for these same groups. Thus, recalling a word increased the probability that it would be completed, and this increase was similar in the three subject groups.

These findings show that amnesia spares the processes that mediate priming across sensory modalities, as well as the specific sensory and perceptual processes that mediate priming within a modality. All groups exhibited significant priming across modalities, but the magnitude of priming was larger under the within-modality condition. The priming effects found in this study are consistent with the findings of previous studies (Graf \& Mandler, 1984; Kirsner et al., 1983; Roediger \& Blaxton, 1983). 
Others have found no evidence for priming across modalities in normal subjects in studies that revealed substantial priming under within-modality conditions (Clarke \& Morton, 1983; Jacoby \& Dallas, 1981; Scarborough et al., 1979; Winnick \& Daniel, 1970). The absence of a priming effect across sensory modalities in these experiments has been viewed as strong evidence that priming is a modality-specific phenomenon. It has been argued that instances of successful priming across sensory modalities are artifacts, mediated by a subject's tendency to image the written version of words while listening to a study list of spoken words (cf. Jacoby \& Witherspoon, 1982). An "imaging" strategy might engage modality-specific visual processes that then mediate priming across modalities. This suggestion was reinforced by the finding that when task instructions focused subjects' attention on visual or written images of spoken words, priming across modalities was sometimes increased (Jacoby \& Witherspoon, 1982; but see Graf \& Mandler, 1984).

One way to examine this possibility, would be to study priming under study-test conditions where the sensory-perceptual overlap between study items and test cues is reduced to a minimum. Instead of cuing with information that had been previously presented (e.g., the initial letters of words), we next cued previously presented words with category labels for those words. Under these conditions, there should be little chance that subjects would image the test cues during presentation of the study list. Thus, this procedure tests whether priming can be semantically or conceptually driven, or whether it is restricted to circumstances where the study items and test cues share the same sensory-perceptual features.

\section{Experiment 2}

Subjects were presented a random list of words belonging to different conceptual categories, and then they were given a priming test. We provided category labels as cues, and subjects were required to generate the first eight exemplars that came to mind (see Kihlstrom, 1980). A free-recall test followed the priming task. This study-test procedure ensured that there was only incidental overlap in sensory and perceptual information between study list items and test cues, because the test cues themselves were never presented in the study list.

\section{Method}

\section{Subjects}

Amnesic patients. Two groups of amnesic patients were tested: the 8 patients with Korsakoff syndrome described in Experiment 1 , and 2 patients who became amnesic as a result of hypotensive episodes. The latter group included Case 1, described in Experiment 1, and Case 3 who became amnesic in 1983, following a period of reduced blood pressure that occurred during major surgery. Case 3 was 43 years old at the time of testing: he had 13 years of formal education, a WAIS IQ of 104 , and a WMS score of 81 . His immediate- and delayed$(12 \mathrm{~min})$ recall score for a prose passage was 5 and 0 segments, respectively.

Control groups. Two groups were used to assess the performance of the amnesic patients, one group consisted of alcoholic patients and the second group consisted of hospital volunteers. The alcoholic control group included 10 men who were participating in alcoholic treatment programs in San Diego County. They had been drinking for an average of 21 years, they had abstained from alcohol for an average of 18 weeks prior to participating in the present study, and they had no history of head injury or liver disease. This group averaged 51.6 years of age (range 37-63), they had an average of 12.5 years of formal education (range 10-14), and they had an average WAIS-R subtest score of 21.4 for information (18.8 for the amnesic patients) and 52.1 for vocabulary (45.3 for the amnesic patients). Immediate- and delayed- (12 min) recall scores for a prose passage was 6.3 and 4.7 (4.4 and 0.4 for amnesic patients). Their recall of 10 unrelated noun-noun pairs on each of three successive trials was $3.9,7.4$, and $8.9(0.5,0.9$, and 1.3 for amnesic patients).

The second group consisted of 8 volunteers, 5 men and 3 women, at the San Diego Veterans Administration Medical Center. None of these subjects had a psychiatric diagnosis, and none had a history of alcoholism. This group averaged 39.6 years of age (range 25-61) and 12.2 years of formal education (range 12-14).

\section{Materials}

The materials were drawn from the Battig and Montague (1969) norms. From each of 12 categories (e.g., $a$ piece of furniture, a fruit, a sport, a part of the human body), we selected five common exemplars (e.g., bookcase, cabinet, bench, rocker, and footstool). The items selected were not ranked among the 10 most frequently produced exemplars for a category, but each item was listed as an exemplar by at least 10 subjects in the sample of 400 subjects used to collect the normative data. On the basis of overall production frequency, the average rank of the selected category exemplars was 23.9 (range 11-46) in the Battig and Montague norms. These 12 sets of 5 words formed the target lists for Experiment 2.

We used the label from each category as a cue for the 
priming tests. We changed some of the category labels slightly from those used in collecting the norms, in order to make them more concrete descriptors of the particular items selected for the experiment (e.g., a kitchen utensil became something used in the kitchen).

\section{Procedure}

Subjects were tested individually. They were first instructed in the liking rating task described in Experiment 1 , and they practiced this task with five unrelated words that were not members of the categories used in the study. Immediately after practice thete were two studytest trials. For each trial, a study list of 15 words was read to the subjects twice in succession in a different random order on each presentation, and subjects rated how much they liked each word. The 15 -word study list was composed of the five exemplars from each of three different target categories. These words were always arranged randomly in the study list. Word presentation was self-paced by each subject's speed on the liking rating task, about 5-s per word.

Immediately after the second presentation of each study list, subjects were given a priming test, followed by a free-recall test. The priming test instructions advised subjects that "we will now do something different. I'm going to give you a title-the name of a category, and I want you to say eight things that belong to that category as fast as you can." To illustrate this word production test, the experimenter provided a label (a relative) and some exemplars (aunt, uncle, sister), and subjects were asked to produce some further exemplars. For the test itself, subjects were given six category labels, one at a time, and they were asked to produce eight exempiars from each category. Eight exemplars were requested from each category in order to ensure that exemplars other than very common ones would be produced.

Three of the six categories were always the ones from which the study items were drawn, and the other three categories were ones whose exemplars had not been presented to the same subject. The six category labels were presented in a random order. The probability of producing the words from the study list on this word production test provided the measure of interest. The probability of producing target words belonging to the other three categories provided a measure of baseline performance for word production. Across subjects, we counterbalanced the categories that were used for the study list and the categories that were used to assess baseline performance.

Following word production, a free-recall test was given. Subjects were reminded that this test concerned the items that they had heard in the study list, and they were asked to write the words from the study list in any order on a blank page. Then there was a short pause (2-3 min) before the second study-test trial was administered. The second study-test trial was administered in the same way as the first, using a new study list and new category labels. Across the subjects in each group, the exemplars from each category were studied and tested equally often on the first and second trial.

In summary, subjects received two study-test trials, each of which involved the presentation of 15 words, followed by a word production test and a free-recall test.
The word production test required subjects to produce eight exemplars for each of six category labels. Three of the categories had provided the 15 study words (five from each category), and three of the categories were used to assess baseline word production performance.

\section{Results and Discussion}

As in Experiment 1, a strict criterion was used in scoring both the free-recall and the word production test forms. Performance on the first and second study-test trials was virtually identical for both free recall and word completion ( $F$ scores less than 1 ), and thus the results from the two trials were averaged for statistical analyses. Figure 2 shows the average recall performance and word production performance for the three subject groups. The average level of recall was similar for the healthy control group (46.2\%) and for the alcoholic group (39.0\%), $t=.76$, but recall performance was substantially lower in the amnesic group (1.0\%). An ANOVA showed a significant main effect for subject groups, $F(2,26)=41.1, M S_{\mathrm{e}}=13.9$.

The three subject groups showed different levels of baseline performance on the word production test, $F(2,26)=6.9, M S_{\mathrm{e}}=2.2$ ( $5.0 \%$ for healthy controls, $11.7 \%$ for alcoholic controls, and $5.3 \%$ for amnesic patients). In order to obtain a measure of priming on the word production test, each subject's score for items for the study list was adjusted by his or her score on the nonpresented items (baseline score). In this way, we obtained a measure of priming that was not influenced by the differences in baseline scores across subject groups. As illustrated in Figure 2, each group showed a significant tendency to generate target words from the study list more often than expected without a study list presentation ( $12.5 \%$ for volunteers, $t(7)=2.55, p<.05$; $11.0 \%$ for alcoholic controls, $t(9)=2.07, p=$ .068 ; and $12.3 \%$ for amnesic patients, $t(9)=$ $4.92, p<.01)$. All groups showed a similar amount of priming, $F(2,25)=.04$.

An analysis of word production performance contingent on subsequent recall performance was performed for the alcoholic and inpatient control groups (the level of recall for the amnesic group was too low to evaluate). Those items that were produced in the priming task were recalled better than items that were not produced. This effect was 


\section{RECALL}

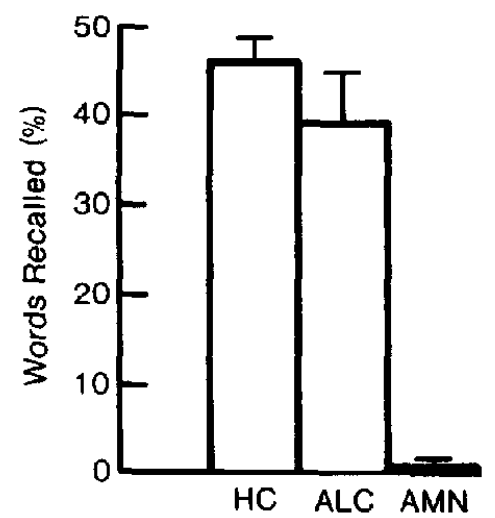

WORD PRODUCTION BY CATEGORY CUES

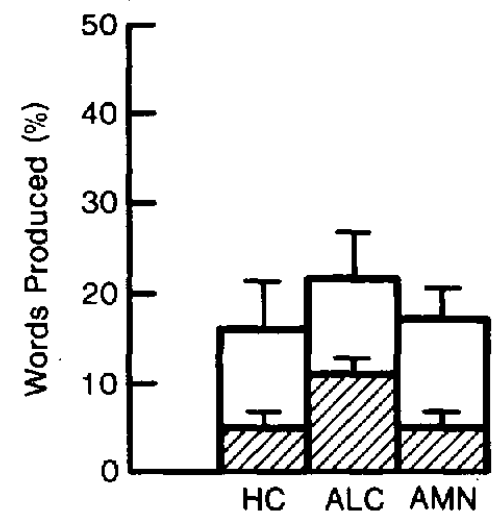

Figure 2. Recall (left) and word production (right) by amnesic patients (AMN), healthy controls (HC), and alcoholic controls (ALC). (The study words were exemplars from different categories, and word production was tested by cueing with category labels. The shaded area of each bar shows baseline performance.)

seen in Experiment 1 in this article as well as in Tulving, Schacter, and Stark (1982).

This pattern of results strengthens the findings from Experiment 1 by showing priming even under conditions where there was only incidental overlap in sensory and perceptual information between study list items and test cues. Because items from different conceptual categories in the study list were ordered randomly, it was unlikely that during study list presentation subjects would have been able to image the cues that were subsequently used on the word production test. Thus, the present findings indicate that overlap in sensory and perceptual information between study list items and test cues is not essential for priming. Moreover, the finding of similar amounts of priming in amnesic patients and in 2 control groups is inconsistent with the view that subjects accomplish priming by using a recall strategy to generate words. If that view were correct, one would have expected amnesic patients, who have a severe deficit in free recall, to exhibit poorer performance on the word production test than the control groups.

\section{General Discussion}

The present findings provide a more detailed description of the conditions under which preserved priming can be observed in amnesic patients. In the word completion test of Experiment 1, amnesic patients showed normal priming under both visual-visual and auditory-visual study-test conditions. Both amnesic patients and control subjects showed a larger priming effect under the withinmodality condition than they showed under the across-modality condition. The results from Experiment 2 strengthen the evidence for priming across sensory modalities by showing normal and significant priming effects in amnesic patients, even under conditions where there is little or no overlap in sensory and perceptual information between study-list items and test cues. Together, these findings illustrate that amnesia preserves not only modality-specific sensory and perceptual processes, but that it also spares processes that mediate the transfer of information across modalities.

The results from Experiment 1 revealed a significant amount of priming across sensory modalities and an even larger amount of priming within a modality. The larger priming effect found under within-modality conditions suggests that the priming phenomenon is mediated to some extent by the specific sensory and perceptual processes that are engaged when words are presented for study. These modality-specific effects may be similar to 
what has been found in other priming paradigms such as lexical decision and word identification tasks (Clarke \& Morton, 1983; Jacoby, 1983; Jacoby \& Dallas, 1981; Scarborough et al., 1979). In lexical decision and word-identification tasks, consistent priming effects that last longer than a second or two occur only when study items and test cues are presented in the same modality. In our experiment, however, and in others (Graf \& Mandler, 1985; Roediger \& Blaxton, 1983), there was priming across modality boundaries that lasted for at least several minutes. Whether or not priming across modalities is observed may depend on the type of test that is used to measure priming. Lexical decision and word identification tasks assess priming under conditions where speed of processing is the key variable. In contrast, priming on word completion tests does not depend on processing speed because subjects are asked simply to complete test cues with the first words that come to mind. These and other test differences may determine the conditions under which priming across modalities is found (see Graf \& Mandler, 1985, for further discussion).

It has been suggested that priming across modalities is an artifact caused by subjects' tendency to invoke visual imagery during the oral presentation of study words (Jacoby \& Witherspoon, 1982). To the extent that subjects used imagery while hearing spoken words, priming across modalities could be mediated by processes specific to the visual mode. Although this suggestion provides one possible account for priming across modalities in Experiment 1, it cannot account for the priming effects found in Experiment 2. In Experiment 2, there was essentially no sensory and perceptual overlap between study items and test cues. In addition, the items from the different categories were ordered randomly in the study list, thus making it unlikely that subjects would discover and image the identity of test cues during study list presentation. Nevertheless, amnesic patients and control groups showed a significant amount of priming. Thus, the finding of priming across sensory modalities is difficult to dismiss as an artifact owing to imaging (Jacoby \& Witherspoon, 1982).
The priming of words by category cues found in Experiment 2 is similar to the finding that amnesic patients can be primed with semantic associates in a word association test (Shimamura \& Squire, 1984). In this test, subjects were first shown words (e.g., child) in an incidental learning task and then asked to free associate to cue words that were semantically related to previously presented words (e.g., baby). Amnesic patients and control subjects exhibited priming of words by semantic associates that was about 2 times greater than baseline. This finding provides a particularly strong argument that imaging of study words cannot account for priming, when study and test cues share no sensory or perceptual features. In the present study, 15 words belonging to three categories were presented, and one might suppose that subjects perceived the three relevant categories and imaged them during list presentation. In the word association study (Shimamura \& Squire, 1984), 12 different words were presented, and each of them was tested separately by presenting a semantic associate. It is highly unlikely that subjects encoded each of these words by imaging its associate.

In word completion tests and word association tests, the priming effect disappeared in amnesic and normal groups after a 2-hr delay (Graf et al., 1984; Shimamura \& Squire, 1984). Some related studies with normal subjects have shown that priming effects can be observed as long as a few days or a week after study list presentation (Jacoby, 1983; Scarborough, Cortese, \& Scarborough, 1977; Tulving et al., 1982). Findings from amnesic patients indicate that they do not exhibit such long-lasting effects, thus raising the possibility that the long-lasting effects are qualitatively different from the effects that are present for a few hours (Squire, Shimamura, \& Graf, 1985b).

Amnesic patients exhibited normal priming effects despite severe deficits on standard tests of memory such as recall and recognition. We suggest that amnesic patients can activate or prime previously presented materials but they lack the ability to elaborate, organize, and consciously recollect information learned since the onset of amnesia. This impairment prevents the establishment of long-lasting 
memories. Priming tests assess the activation of previously presented materials without asking subjects explicitly to retrieve from memory. Priming tests are designed to emphasize the effects of automatic activation on performance and to minimize the effects of elaboration, organization, and conscious recollection. When tests prevent these latter effects, amnesic patients perform normally. This view is also consistent with the finding that instructions that emphasize recalling items from a study list improve the performance of normal subjects compared with when implicit or priming test instructions are given. Amnesic patients, however, are not affected by this change in instructions (Graf et al., 1984; Shimamura \& Squire, 1984).

The present findings for amnesic patients should not be compared directly with the findings obtained from subjects exhibiting hypnotically induced amnesia (Kihlstrom, 1980). These subjects were presented words during hypnosis and were then instructed that they would be unable to remember the same words until a specific command was given. Upon awakening from hypnosis, free recall of words was impaired, but there was no effect on priming when the same words were cued by category labels or by semantic associates. After the suggestion to forget the study words was lifted by giving the command, the subjects recalled as many words as control subjects. In this case, one must conclude that hypnotically induced amnesia produced a failure to retrieve information rather than a failure to store information during hypnosis. Because no test procedures have ever produced normal free-recall performance in the organic amnesia associated with brain injury or disease, it is difficult to make direct comparisons between hyponotically induced amnesia and organic amnesia.

Recent studies of memory and the brain have developed the perspective that amnesia reflects damage to a specific brain system that is required for information to be elaborated, consolidated, and available to conscious recall (Baddeley, 1982; Mishkin et al., 1984; Moscovitch, 1982; Squire, 1982a). Priming and skill learning are spared in amnesia because they do not depend on this brain system and because in these cases elaboration, consolidation, and conscious recollection are not required for the effects of experience to be expressed. The present findings, together with related findings (Graf et al., 1984; Shimamura \& Squire, 1984; Squire et al., 1985a), show that amnesic patients exhibit normal priming across modality boundaries and normal priming when cued by category labels or semantic associates. Moreover, because amnesic patients can exhibit chance performance on recognition memory tests at the same time that priming is intact (Squire et al., 1985a), we suppose that the processes that support priming can be independent of the processes that support performance on conventional memory tests.

\section{References}

Baddeley, A. (1982). Implications of neuropsychological evidence for theories of normal memory. Philosophical Transactions of the Royal Society of London, 298, 5972.

Battig, W. F., \& Montague, W. E. (1969). Category norms of verbal items in 56 categories: A replication and extension of the Connecticut category norms. Journal of Experimental Psychology Monographs, 80 (3, Pt. 2).

Brooks, D. N., \& Baddeley, A. (1976). What can amnesic patients learn? Neuropsychologia, 14, 111-122.

Cermak, L. S. (1982). Human memory and amnesia. HIlsdale, NJ: Erlbaum.

Clarke, R., \& Morton, J. (1983). Cross modality facilitation in tachistoscopic word recognition. Quarterly Journal of Experimental Psychology, 35A, 79-96.

Cofer, N. C. (1967). Conditions for the use of verbal associates. Psychological Bulletin, 68, 1-12.

Cohen, N. J. (1984). Preserved learning capacity in amnesia: Evidence for multiple memory systems. In L. Squire \& N. Butters (Eds.), The neuropsychology of memory (pp. 83-103). New York: Guilford Press.

Cohen, N. J., \& Squire, L. R. (1980). Preserved learning and retention of pattern analyzing skill in amnesia: Association of knowing how and knowing that. Science, 210, 207-209.

Cohen, N. J., \& Squire, L. R. (1981). Retrograde amnesia and remote memory impairment. Neuropsychologia, 19, 337-356.

Corkin, S. (1968). Acquisition of motor skill after bilateral medial temporal lobe excision. Neuropsychologia, 6, 225-265.

Cramer, P. (1966). Mediated priming of associative responses: The effect of time lapse and interpolated activity. Journal of Verbal Learning and Verbal Behavior, 5, 103-166.

Diamond, R., \& Rozin, P. (1984). Activation of existing memories in the amnesic syndromes. Journal of $A b$ normal Psychology, 93, 98-105.

Forster, K. I. (1976). Accessing the mental lexicon. In R. J. Wales \& E. Walker (Eds.), New approaches to language mechanisms. Amsterdam: North-Holland. 
Graf, P., \& Mandler, G. (1984). Activation makes words more accessible, but not necessarily more retrievable. Journal of Verbal Learning and Verbal Behavior, 23, 553-568.

Graf, P., \& Mandler, G. (1985). Direct priming across sensory modalities and word boundaries. Manuscript submitted for publication.

Graf, P., Squire, L. R., \& Mandler, G. (1984). The information that amnesic patients do not forget. Journal of Experimental Psychology: Learning, Memory, and Cognition, 10(1), 164-178.

Jacoby, L. L. (1983). Perceptual enhancement: Persistent effects of an experience. Journal of Experimental Psychology: Learning. Memory, and Cognition, 9, 21-38.

Jacoby, L. L., \& Dallas, M. (1981). On the relationship between autobiographical memory and perceptual learning. Journal of Experimental Psychology: General, $110,306-340$.

Jacoby, L. L., \& Witherspoon, D. (1982). Remembering without awareness. Canadian Journal of Psychology. 32, 300-324.

Kihlstrom, J. F. (1980). Posthypnotic amnesia for recently learned material: Interactions with "episodic" and "semantic" memory. Cognitive Psychology, 12, 227251.

Kirsner, K., Milech, D., \& Standen, P. (1983). Common and modality-specific processes in the mental lexicon. Memory \& Cognition. 11, 621-630.

Kučra, M., \& Francis, W. (1967). Computational analysis of present-day American English. Providence, RI: Brown University Press.

Mishkin, M., Malamut, B., \& Bachevalier, J. (1984). Memories and habits: Two neural systems. In $G$. Lynch, J. L. McGaugh, \& N. M. Weinberger (Eds.), Neurobiology of learning and memory (pp. 65-77). New York: Guilford Press.

Mortensen, E. L. (1980). The effects of partial information in amnesic and normal subjects. Scandinavian Journal of Psychology, 21, 75-82.

Morton, J. (1969). The interaction of information in word recognition. Psychological Review, 76, 165-178.

Morton, J. (1979). Facilitation in word recognition: Experiments causing change in the logogen models. In P. A. Kolers, M. E. Wrolstad, \& H. Bouma (Eds.), Processing of visible language (Vol. 1, pp. 259-268). New York: Plenum.

Moscovitch, M. (1982). Multiple dissociations of function in amnesia. In L. Cermak (Ed.), Human memory and amnesia (pp. 337-370). Hillsdale, NJ: Erlbaum.

Roediger III, H., \& Blaxton, T. A. (1983, November). Priming in word fragment completion: Effects of modality and orthography. Paper presented at the 24th annual meeting of the Psychonomic Society, San Diego, CA.

Rozin, P. (1976). The psychobiological approach to human memory. In M. R. Rosenzweig \& E. L. Bennett (Eds.), Neural mechanisms of learning and memory (pp. 346). Cambridge, MA: MIT Press.

Scarborough, D. L., Cortese, C., \& Scarborough, H. (1977). Frequency and repetition effects in lexical memory. Journal of Experimental Psychology: Human Perception and Performance, 3, 1-17.

Scarborough, D. L., Gerard, L., \& Cortese, C. (1979). Accessing lexical memory: The transfer of word repetition effects across tasks and modality. Memory \& Cognition, 7, 3-12.

Schacter, D. L. (in press). Priming of old and new knowledge in amnesic patients and normal subjects. In D. Olton, S. Corkin, E. Gamzu (Eds.), Conference on memory dysfunctions. New York: New York Academy of Sciences.

Shimamura, A. P., \& Squire, L. R. (1984). Pairedassociate learning and priming effects in amnesia: $A$ neuropsychological study. Journal of Experimental Psychology: General, 113, 556-570.

Squire, L. R. (1982a). The neuropsychology of human memory. Annual Review of Neuroscience, 5, 241-273.

Squire, L. R. (1982b). Comparisons between forms of amnesia: Some deficits are unique to Korsakoff's syndrome. Journal of Experimental Psychology: Learning, Memory, and Cognition, 8, 560-571.

Squire, L. R., \& Butters, N. (Eds.). (1984). Neuropsychology of memory. New York: Guilford Press.

Squire, L. R., \& Cohen, N. J. (1984). Human memory and amnesia. In G. Lynch, J. L. McGaugh, \& N. M. Weinberger (Eds.), Neurobiology of learning and memory (pp. 3-64). New York: Guilford Press.

Squire, L. R., Shimamura, A., \& Graf, P. (1985a). Independence of recognition memory and priming effects: A neuropsychological analysis. Journal of Experimental Psychology: Learning, Memory, and Cognition, $11,37-44$.

Squire, L. R., Shimamura, A. P., \& Graf, P. (1985b). The duration of priming effects in normal subjects and amnesic patients. Manuscript submitted for publication.

Talland, G. A. (1965). Deranged memory. New York: Acadernic Press.

Tulving, E., Schacter, D., \& Stark, H. A. (1982). Priming effects in word-fragment completion are independent of recognition memory. Journal of Experimental Psychology: Learning. Memory, and Cognition, 8, 352373.

Warrington, E. K., \& Weiskrantz, L. (1970). The amnesic syndrome: Consolidation or retrieval? Nature, 228 , 628-630.

Warrington, E. K., \& Weiskrantz, L. (1974). The effect of prior learning on subsequent retention in amnesic patients. Neuropsychologia, 12, 419-428.

Warrington, E. K., \& Weiskrantz, L. (1978). Further analysis of the prior learning effect in amnesic patients. Neuropsychologia, 16, 169-177.

Winnick, W. A., \& Daniel, S. A. (1970). Two kinds of response priming in tachistoscopic recognition. Journal of Experimental Psychology, 84, 74-81.

Received August 3, 1984

Revision received November 12, 1984 